\title{
Thermal Stability of a Eutectic Mixture of Bis(2,2-dinitropropyl)acetal and Bis(2,2- dinitropropyl)formal: Part B. Degradation Mechanisms under Water and High Humidity Environments
}

\author{
Dali Yang ${ }^{1)^{*}}$, Robin Pacheco ${ }^{l)}$, Stephanie Edwards ${ }^{1)}$, Joseph Torres ${ }^{l)}$, Kevin Henderson ${ }^{l)}$, \\ Milan Sykora ${ }^{2}$, Peter Stark ${ }^{2}$, and Sheldon Larson ${ }^{3)}$ \\ ${ }^{1)}$ Materials Science and Technology, \\ ${ }^{2)}$ Chemistry and \\ 3) Explosive Science and Shock Physics Divisions \\ Los Alamos National Laboratory, Los Alamos, New Mexico, 87545
}

\begin{abstract}
As a continuation of our effort to understand degradation mechanisms of a eutectic mixture of bis(2,2-dinitropropyl)acetal (BDNPA) and bis(2,2dinitropropyl)formal (BDNPF) (referred to as NP) under various environmental conditions, we investigated the thermal stability of NP under water and $74 \%$ relative humidity (RH) environments at temperatures below $70^{\circ} \mathrm{C}$. Based on a comprehensive characterization of samples aged over a period of two years, we conclude that in the presence of water the reaction pathways of the NP degradation are different from those observed in air or under nitrogen atmosphere. We found that the physical state of water molecules plays an important role as it determines the ability of oxygen to participate in the NP aging process. Based on the results obtained in Parts A and B of these studies, we conclude that the rate of NP degradation increases in the order: nitrogen < water < air < water vapor + air.
\end{abstract}

Key words: Nitroplasticizer, BDNPA, BDNPF, Condensed phase, Estane, Stability, Degradation

\section{Introduction}

In Part A of this series, we investigated the mechanism and dynamics of chemical

\footnotetext{
*Corresponding author: D. Yang (dyang@lanl.gov), phone: 1-505-665-4054.
} 
degradation of NP in air and under nitrogen atmosphere.[1] In addition to air and nitrogen, plastic-bonded explosive (PBX) materials, such as PBX 9501, are often exposed to other types of environments, such as humidity. In the PBX 9501 formula, two binders are used. One is Estane [poly(ester urethane)] and the other is a eutectic mixture of bis(2,2-dinitropropyl)acetal (BDNPA) and bis(2,2-dinitropropyl)formal (BDNPF). The mixture is referred to as NP. From previous studies of Estane it is known that when it is exposed to water and/or moisture, hydrolysis occurs at ester functional groups, which leads to breaking of polymer chains. This chain scission results in the formation of low molecular weight Estane with poor mechanical properties and undesirable performance of PBX 9501.[2-7] While the effect of humidity and water on Estane is well understood, its effect on NP has not yet been reported. More importantly, lack of information about the mechanism of NP degradation makes it difficult to make predictions about the effects of potentially important interactions between the byproducts of the NP degradation and Estane and other components of the PBX 9501 mixture in humid environment. Early findings that NP was insoluble in water,[8] suggested that interaction between water and NP may not be significant. However, in more recent study, Salazar reported that the water uptake in NP while limited, increases from 0.9 to $2.5 \mathrm{mg} / \mathrm{gram}$ of sample when the relative humidity increases from 50 to 94\%.[9] In high humidity water often condenses within the micropores of the matrix, such as PBX 9501. Nevertheless, the effects of the long-term exposure of NP to humidity and water on its composition and properties has not been investigated. To fill this gap, we, here, conducted a systematic study where the NP samples were aged under water or high humidity environments. The condensed phases of the aged samples were characterized using TGA, FTIR, GPC, and ESI-mass spectroscopy techniques. The combination of these complementary methods provides valuable insights into the mechanism and the dynamics of NP degradation in contact with vapor and liquid water at various temperatures.

\section{Experimental}

The details of the experimental conditions and characterization methods were documented in Part A of this series. Here, we only summarize the differences in the sample preparation. 
To simulate the water exposure conditions, NP was placed into a glass vial, which was placed inside of a PTFE container. A small amount of deionized water was added to the top of the liquid NP. Since baseline NP is a limited solubility in water, $[8,9]$ clear interface between the two liquids was observed. Because of its higher density, the NP $\left(\sim 1.39 \mathrm{~g} / \mathrm{cm}^{3}\right)[10]$ remained at the bottom of the vial for the duration of the experiment. To prevent evaporation of the water from the vial, small amount of water was maintained within the PTFE container outside of the vial ( $1 / 3$ height of the vial). To investigate the temperature effect, the closed containers were placed in 55 and $70{ }^{\circ} \mathrm{C}$ ovens, respectively. The third container, as a set of control samples, was stored at room temperature. For physical measurements (TGA, FTIR, GPC) performed at various aging times, the samples were withdrawn from the bottom portion of the vials using a disposable pipet. After the sample extraction, a small amount of water was added to ensure the full coverage on the top of the NP sample. At the end of the aging study (24 months), samples were further analyzed using ESI-Mass spectrometry (ESI-MS) and ${ }^{1} \mathrm{H}$ NMR. To simplify discussion, we will refer to these samples as hydrated NPs.

The other set of aged NP samples was prepared from the previously investigation,[11] in which PBX 9501 had aged under $74 \%$ relative humidity $(\mathrm{RH})$ at $70{ }^{\circ} \mathrm{C}$ for different periods of time. In that study, the PBX 9501 samples were thermally aged inside containers sealed in air. Saturated $\mathrm{NaCl}$ aqueous solutions were used to produce the $74 \%$ relative humidity.[12] To maintain NP vapor pressure, a bottle of liquid NP (>100 ml) was placed inside each container. Total six containers were prepared and were sequentially removed from the oven maintained at $70{ }^{\circ} \mathrm{C}$ at various aging times. The aged PBX 9501 and NP samples were collected as early as 18 days. Due to the significant degradation of the PBX 9501 samples, the aging experiment was terminated after 125 days. More detailed description about the experimental setup and characterization of the aged PBX 9501 samples was reported previously.[11, 13, 14] The aged NP samples were analyzed using TGA and FTIR. To differ this set of samples from the above samples, we will refer to these samples as moisturized NPs.

\section{Results and Discussion}

\subsection{Visual Observation and TGA of Hydrated Samples}


Figure 1 shows the color changes observed for the hydrated NPs thermally aged at indicated conditions. After 12 months of aging, the color of the samples changes from brown to dark brown or orange as the temperature increases from RT to 55 and $70{ }^{\circ} \mathrm{C}$, respectively. Additional aging at the $\mathrm{RT}$ and $55{ }^{\circ} \mathrm{C}$ does not lead to observable color changes. However, in the case of the $70{ }^{\circ} \mathrm{C}$ sample, after 12 months, the color continues changing to light orange and sample starts developing a strong acidic odor. Due to the poor solubility of water in the baseline NP, a clear interface was observed between the two liquids at the beginning of aging. Although this interface is visible after aging, the degree of the transparency of the aged samples decreases, which suggests the property changes. This is especially true for the 55 and $70{ }^{\circ} \mathrm{C}$ samples. On the other hand, it is conceivable that some water-soluble molecules from the NP phase are extracted into the water phase during the aging process.

Figure 2 compares the TGA results for three samples aged at $70{ }^{\circ} \mathrm{C}$ for 24 months in various environments. As expected, Air sample shows the poorest thermal stability. Interestingly, the hydrated (water) sample appears to be the most thermally stable. We suspect that the extraction of some water-soluble molecules from the hydrated NP is partially responsible for its slightly increased stability.

\subsection{FTIR Spectroscopy of Hydrated Samples}

\subsubsection{Role of the environment}

Figure 3 shows the FTIR spectra of the same samples as shown in Figure 2. In the high wavenumber region (H-region), the new band associated with poly-alcohol groups (poly-OHs) at $\sim 3250 \mathrm{~cm}^{-1}$ are detected for all three samples. While the $\mathrm{N}_{2}$ sample gives the smallest intensity of the poly-OH band, the Air sample gives the highest intensity of this band. Additionally, the Air sample also gives the highest intensity of free hydrogen bonded - $\mathrm{OH}$ (referred to as free-OH) groups at $3600 \mathrm{~cm}^{-1}$.[15] The spectral changes suggest the formation of a significant amount of the poly-OHs in all the aged samples regardless of the environments. However, the Air sample might contain the highest amount of the poly-OHs. Accordingly, weak new features between $\sim 3200$ and $\sim 3050 \mathrm{~cm}^{-}$ ${ }^{1}$ are observed in all the aged samples. The small peak at $3070 \mathrm{~cm}^{-1}$, associated with a $v(>\mathrm{C}=\mathrm{C}-\mathrm{H})$ group, suggests the presence of bis-2,2-nitro-propylene acetal (BNPeA)/ bis- 
2,2-nitro-propylene formal $(\mathrm{BNPeF})$ in all the aged samples. These intermediates are produced from the HONO elimination from BDNPA/F.[1] Interestingly, these three samples give different spectral features between 3010 and $2800 \mathrm{~cm}^{-1}$. The spectra of both Air and $\mathrm{N}_{2}$ samples are dominated by a strong BDNPF feature (between 3050 and 2800 $\mathrm{cm}^{-1}$ ), suggesting that the degradation more preferentially affect the BDNPA than BDNPF molecules.[1] On the other hand, this preferential trend is not clearly observed in the hydrate sample. Instead, the fine features between 3000 and $2920 \mathrm{~cm}^{-1}$ suggest the formation of new $-\mathrm{CH}$ group in the hydrate sample, which indicates that the degradation mechanism of NP in the water environment is different from that occurring under the dry environments.

In the low wavenumber region (L-region), both hydrated and $\mathrm{N}_{2}$ samples yield almost identical spectra. The intensities of the peaks in the $1800-1600 \mathrm{~cm}^{-1}$ range increase slightly with aging, which suggests formation of small amounts of free- $\mathrm{OH},-\mathrm{CN}$, and $>\mathrm{C}=\mathrm{C}<$ functional groups. The observation of the $-\mathrm{NO}$ peak at $1505 \mathrm{~cm}^{-1}$ in all aged samples suggests that structural rearrangement and formation of the BDNPA/F isomers takes place in all studied environments. Compared to the spectrum of baseline NP, the characteristic peaks of BDNPA at 1093 and $1014 \mathrm{~cm}^{-1}$ (-C-O-) and at $910 \mathrm{~cm}^{-1}$ (-CNO) in the hydrated NP change in a way similar to those in the $\mathrm{N}_{2}$ sample. This suggests that BDNPA degrades similarly when NP is exposed to either nitrogen or liquid water, and BDNPA degrades more rapidly than BDNPF. On the other hand, the newly formed $>\mathrm{C}=\mathrm{O}$ peaks between 1800 and $1600 \mathrm{~cm}^{-1}$ and disappearance of peaks at 1090 and 910 $\mathrm{cm}^{-1}$ in the spectrum of the Air suggest that the baseline NP severely degrades when it is exposed in air at $70{ }^{\circ} \mathrm{C}$ for 24 months.

\subsubsection{Aging and Temperature effects}

Figure 4 shows the FTIR spectra of hydrated samples aged at various temperatures and periods of time. Regardless of the temperatures, the spectral changes are not significantly during the first 3 months. After 6 months of aging, small peaks at $~ 3600$ $\mathrm{cm}^{-1}$, associated with the free-OHs, are detected.[15] However, there is no detectable absorbance at $\sim 3400 \mathrm{~cm}^{-1}$, associated with liquid water molecule.[16] This observation confirms the absence of the detectable amount of liquid water in the NP samples after the 
samples had been directly contacted with water for 6 months, and suggests that the effect of temperature on the water solubility in the NP is insignificant. However, the weak but detectable absorbance at $\sim 3600 \mathrm{~cm}^{-1}$ suggests that the amount of the free-OH increases in the aged samples. We suspect that after the samples being aged for 6 months, some BDNPA/F start to change into BNPeA/F though the HONO elimination.[1] When HONO molecules decompose, water will be produced. At the early stage, the water molecules are isolated and dispersed in the hydrated samples without much H-bonding interaction, which may be responsible for the free-OH peaks. After 12 months, a band between 3350 and 3150 with a peak at $\sim 3250 \mathrm{~cm}^{-1}$, associated with the poly-OHs, is detected and its intensity increases as the temperature increases from RT to $70{ }^{\circ} \mathrm{C}$. This observation is unique to these hydrated samples. As the intensity of the poly-OH band increases at $3250 \mathrm{~cm}^{-1}$, the intensities of three $-\mathrm{CH}_{\mathrm{n}}$ peaks increase accordingly. Furthermore, a new band at $3400 \mathrm{~cm}^{-1}$, associated with liquid water molecules, emerges in the spectrum of the $70{ }^{\circ} \mathrm{C}$ sample as well. Unlike to the spectra of the 6-month aged samples, the spectra of the 12-month aged samples show some changes in the L-region as well. The peaks at 1093 and $910 \mathrm{~cm}^{-1}$, associated with BDNPA, decrease, which suggests the beginning of the BDNPA degradation over BDNPF. After 18 months, the spectral changes in the H-region become even more pronounced. As the band at $\sim 3250$ $\mathrm{cm}^{-1}$ further grows, the band at $3400 \mathrm{~cm}^{-1}$ significantly grows so that the latter band gives a higher intensity than the former one in all three samples. This observation suggests that the formation of the poly-OHs increases the solubility of water in the hydrated samples. The presence of water leads to observation of a dominant band at $3400 \mathrm{~cm}^{-1}$. As the temperature increases from RT to $70{ }^{\circ} \mathrm{C}$, the increase in the intensities of both bands at 3400 and $3250 \mathrm{~cm}^{-1}$ suggest that thermal energy aids the formation of poly-OH and increases the solubility of water in the hydrated samples. The increase in water content decreases the viscosity of the hydrated samples and results in the increased intensities of three $-\mathrm{CH}_{\mathrm{n}}$ peaks. In the L-region, the intensities of peaks between 1800 and $1600 \mathrm{~cm}^{-1}$ increase. The intensity of the bands at $\delta_{\mathrm{as}}\left(-\mathrm{CH}_{3}\right)\left(1464 \mathrm{~cm}^{-1}\right), \delta_{\mathrm{s}}-\mathrm{COC}-\left(1090 \mathrm{~cm}^{-1}\right)$, and $v(\mathrm{~N}-\mathrm{O})\left(910 \mathrm{~cm}^{-1}\right)$, associated with in the BDNPA, decrease. The spectral changes in the 55 and $70{ }^{\circ} \mathrm{C}$ samples are more pronounced than in the RT sample. After 24 months of aging, the poly-OH peak continues growing. While the band at $3400 \mathrm{~cm}^{-1}$ is a dominant 
feature in the spectrum of the RT samples, the poly-OH band at $3250 \mathrm{~cm}^{-1}$ becomes a dominant feature in the spectra of both 55 and $70{ }^{\circ} \mathrm{C}$ samples. These results suggest that elevated temperature accelerates the degradation of the hydrated NPs. Accordingly, the peak at $2998 \mathrm{~cm}^{-1}\left(-\mathrm{CH}_{3}\right)$ becomes a shoulder while the characteristic peak at $\sim 2970 \mathrm{~cm}^{-}$ ${ }^{1}$, associated with the BDNPF, grows and becomes a detectable peak in the $70{ }^{\circ} \mathrm{C}$ sample. In the L-region, the overall changes are similar to those observed from the 18-month aged samples. The intensities of all the characteristic bands associated with the BDNPA further decrease. These spectral changes confirm that BDNPA degrades more rapidly than BDNPF when the NP is thermally aged under water environment.

\subsection{GPC Characterization}

Figure 5 shows the GPC results for the hydrated samples aged at 55 and $70{ }^{\circ} \mathrm{C}$ for 24 months. The key observation is a decrease in the intensity of the main peak with increasing temperature, which suggests a decrease in the NP concentration. In addition, for the $70{ }^{\circ} \mathrm{C}$ sample, two small peaks can be seen to grow at the low molecular weight end, indicating formation of degradation products. The two aged samples do not contain a detectable amount of PBNA.

Figure 6 shows the GPC results for the three NP samples aged at different environments and at $70{ }^{\circ} \mathrm{C}$ for 24 months. When compared to the baseline NP, the signal associated with the $\mathrm{N}_{2}$ sample changes the least, whereas the signal of the Air sample changes the most. Therefore, the GPC results, consistent with the TGA results in Figure 2 and the FTIR results in Figure 3, also suggest that the rate of NP degradation increases in following order: nitrogen < water < air, when the baseline NPs are aged at the same temperature for the same period of time.

\subsection{ESI-MS Characterization}

To identify the degradation products, we analyzed the aged samples using ESI-MS. Figures 7(a) and (b) shows the ESI-MS spectra for the baseline NP, hydrated, $\mathrm{N}_{2}$, and Air samples aged at $70{ }^{\circ} \mathrm{C}$ for 24 months. Except for small differences in the intensities of some of the peaks, the spectra of hydrated and $\mathrm{N}_{2}$ samples are similar, as shown in Figure 7(a). It is especially true for the compounds and clusters with $\mathrm{m} / \mathrm{z}>150$. Interestingly, 
the intensity ratio of the peaks attributed to BDNPF and BDNPA in the hydrated NP is slightly higher than in the NP sample aged under $\mathrm{N}_{2}$. This observation not only confirms the preferential degradation of BDNPA over BDNPF in the water environment, but also suggests that this preferential trend is actually more pronounced in the presence of water than under dry nitrogen atmosphere. Furthermore, the intensities of the peaks at $\mathrm{m} / \mathrm{z}=$ 256-260 in the hydrated sample are higher than those in the $\mathrm{N}_{2}$ sample, which suggests the former samples contains a more newly formed compounds than the latter sample. In contrast, since the intensities of peaks at $\mathrm{m} / \mathrm{z}=\sim 230$ and $\sim 303$, associated with the transstate compounds found in BDNPA, in the hydrated sample are slightly smaller than those in the $\mathrm{N}_{2}$ sample, we conclude that the presence of water accelerates the conversion of the BDNPA into the nitroso alcohol isomer.[1] In the $\mathrm{m} / \mathrm{z}<150$ range, the hydrated sample yields peaks found in both the $\mathrm{N}_{2}$ and Air samples as well. The intensities of the peaks at $\mathrm{m} / \mathrm{z}=30,41-42,55-57,65-68,93,118$ and 134 are clearly higher than those observed in the $\mathrm{N}_{2}$ sample, but lower than in the Air sample, as shown in Figure 7(b). While the peaks at 55-57, 65-68, 93-95, and 118 are attributed to the acidic water clusters, the rest are attributed to the decomposed molecules found in the Air sample. Since we prepared the hydrated samples in air, the samples initially contained oxygen. It is also worth noting that the aged samples were in continuous contact with water during the aging experiment. As a result, some water-soluble molecules could be extracted into the aqueous phase, which might result in their lower than expected concentrations in the NP phase. On the other hand, the intensities of the peaks directly associated with water molecules, such as $\mathrm{m} / \mathrm{z}=55-95$, are slightly higher than those found in the baseline NP, which suggests the increased water solubility in the hydrated samples. However, their intensities are smaller than those found in the Air sample, which suggests that the water concentration in the hydrated sample is less than that in the Air sample. These observations confirm the limited solubility of water in the hydrated samples even the samples were contacted with water during the aging experiment.

\subsection{Proposed Degradation Pathways in the Presence of Water}

In Part A of this series, we proposed reaction pathways for the degradation of NP in air or under nitrogen atmosphere, summarized in Schemes A.1-A.6,[1] and concluded 
that the elimination of an HONO fragment is an initial step in the NP degradation at the moderate temperatures $\left(<70^{\circ} \mathrm{C}\right)$. However, $\mathrm{HONO}$ is not stable and can react either with $\mathrm{BNPeA} / \mathrm{F}$ to form nitroso alcohol isomers of BDNPA/F, as shown in Scheme A.1; or decompose into small molecules, as shown in Scheme B.1. In the presence of the water molecules, reactions (b) and (c) in Scheme B.1 are less favorable whereas more nitroxyl and nitric acid are more favorable. The enhancement of the peak at $\mathrm{m} / \mathrm{z}=118$ in the ESIMS spectrum of the hydrated sample suggests the increased quantities of $\left\{\mathrm{HNO}_{3}+\right.$ water cluster. Although water has a limited solubility in the baseline NP, H-bond interactions between the $-\mathrm{NO}_{2}$ groups and water and its clusters can enhance the water solubility in the hydrated NPs. This interaction accelerates the formation of the isomer as manifested in the growth of the poly-OH band in the FTIR spectrum of the samples hydrated for 12 months, regardless of the temperature, as shown in Figure 4. The formation of the poly-OH groups further enhances the water solubility in the hydrated NPs, which leads to an appearance of a distinct peak at $3400 \mathrm{~cm}^{-1}$ in the FTIR spectra of the samples aged for 18 months. The increased water solubility likely leads to acceleration of the NP degradation as the FTIR spectra of the samples aged for 24 months show significant changes. It is especially true for the samples aged at 55 and $70{ }^{\circ} \mathrm{C}$. At higher temperatures the presence of acidic molecules may also aid in the formation of double bonds within BNPeA/F to yield new types of nitro alcohol compounds, as shown in Scheme B.2. Therefore, the increased intensity at $\mathrm{m} / \mathrm{z}=256-260$ can be attributed not only to the cluster of $\{\mathrm{BNPeF}+$ water $\}$, but also to the contribution from the nitro alcohol compound formed according to reaction (c.1"). The newly types of nitro alcohol compounds is also partially responsible for the significant growth of the poly-OH band in the FTIR spectrum of the 24-month hydrated sample, apparent in Figure 4. Since the peaks at $\mathrm{m} / \mathrm{z}=270-274$, corresponding to the product of BNPeA, are rather weak, we suspect its further decomposition into 1-nitro-2-propanone $(\mathrm{Mw}=103)$ and acetaldehyde according to reactions (a.2") and (a.3"), as shown in Schema B.2. Furthermore, there is no detectable oxime band in the FTIR spectrum, the higher intensity of the peak at $\mathrm{m} / \mathrm{z}=$ 105 in the hydrated sample, compared to that of the Air sample. This observation suggests the formation of 1-nitro-2-propanone, instead of forming oxime. Similarly, the product of reaction (c.1") might further decompose into smaller molecules through 
reactions (c.2"/c.3"), though their reactivity might be smaller than in case of reactions (a.2"/a.3"). The new reaction pathways proposed in Scheme B.2 explain the additional acceleration on the BDNPA degradation over BDNPF when we compare the water environment to the $\mathrm{N}_{2}$ atmosphere. The new compounds from reactions (a.1") and (c.1") are responsible not only for the significant enhancement of the band at $\sim 3250 \mathrm{~cm}^{-1}$, but also for the spectral changes at $\sim 2950 \mathrm{~cm}^{-1}$ in the FTIR spectrum, as shown in Figure 4. Furthermore, the presence of the peak at $\mathrm{m} / \mathrm{z}=42$ in the hydrated sample suggests that some of BDNPA also degrades from oxime into ethenimine according to reaction (a.5), as shown in Scheme A.2 in Part A of our study.[1] Since the intensity of this oxime peak in the hydrated sample is much smaller than in the Air sample, we conclude that the degradation rate of BDNPA through reaction (a.5) in water is smaller than in air at the same temperature.

It is worth noting that the water layer not only extracts small molecules from the NP to the aqueous phase, but also precludes more oxygen from reacting with the aged sample. After the oxygen molecules, initially present in the $\mathrm{H}_{2} \mathrm{O}$ layer, are scavenged, the aging under the water resembles the conditions similar to those produced by an inert environment. Therefore, the behavior of the hydrated sample resembles more closely that of the $\mathrm{N}_{2}$ sample than the Air sample. However, constantly contacting with water gradually changes the NP properties. The available water molecules will degrade BDNPA/F through reactions (a.1" - a.3") and (c.1" - c.3"), and decreases the thermal stability of NP.

\subsection{NP Aged under Humidity Condition}

Finally, we will discuss the results of the NP samples aged under $74 \% \mathrm{RH}$, at $70{ }^{\circ} \mathrm{C}$. The changes in the color of the samples observed during the aging are shown in Figure 8. The color of the aged NPs changes from brown to dark brown, brown, or light brown over 112 days. The changes in the color of the aged samples are more rapid than those observed for the NP sample stored under water at $70{ }^{\circ} \mathrm{C}$. The TGA results, shown in Figure 9, reveal notable changes in the composition of sample aged for 18-days. As the aging time increases, the thermal stability of the sample, instead of decreasing, increases. Figure 10 shows the comparison of the FTIR spectra of the baseline and aged NPs. After 
the exposure to the moisture at $70{ }^{\circ} \mathrm{C}$ for 18 days, the spectral changes are apparent, similar to changes occurring in the hydrated sample aged for 12 months at $70{ }^{\circ} \mathrm{C}$. In the $\mathrm{H}$-region, the peaks at $3600 \mathrm{~cm}^{-1}$, associated with the free-OH groups, grow. The band at $3250 \mathrm{~cm}^{-1}$ becomes visible. In addition, new weak features emerge at 3050 and $3200 \mathrm{~cm}^{-}$ 1. A weak band at $3120 \mathrm{~cm}^{-1}$ is tentatively attributed to the $-\mathrm{OH} \bullet \bullet \mathrm{O}=\mathrm{C} \mathrm{H}$-bonding interaction. A weak band at $3050 \mathrm{~cm}^{-1}$ is attributed to the $v(>\mathrm{C}=\mathrm{C}-\mathrm{H})$ group. Compared to the baseline NP, the intensities of the bands between $3010-2920 \mathrm{~cm}^{-1}$ are greatly enhanced even though the sample was only aged for 18 days. The spectral changes observed in the range between 3010 and $2920 \mathrm{~cm}^{-1}$ are different from those observed for the Air, $\mathrm{N}_{2}$, and hydrated samples. The appearance of a small shoulder at $\sim 2850 \mathrm{~cm}^{-1}$, associated with the $v_{\text {as }}\left(-\mathrm{CH}-\mathrm{CH}_{3}\right)$, is attributed to the compounds formed by reactions (a.1") and (c.1") in Scheme B.2. The peak at $2670 \mathrm{~cm}^{-1}$, tentatively attributed to the Hbond between $-\mathrm{OH}$ and $>\mathrm{C}=\mathrm{O}$, increases in intensity. In the L-region, the intensity of the bands in the $1800-1600 \mathrm{~cm}^{-1}$ region slightly increases, suggesting the presence of trace amounts of $-\mathrm{OH},>\mathrm{C}=\mathrm{O},-\mathrm{COO}-,-\mathrm{CN}$, and $>\mathrm{C}=\mathrm{C}<$ functional groups. The appearance of the band at $1505 \mathrm{~cm}^{-1}$, attributed to the -NO group, suggests that the structural rearrangement already took place within such a short period of time and the isomers of BDNPA/F had already formed. Compared to the baseline NP, all the bands associated with the $-\mathrm{NO}_{2}$ group are weaker, and the characteristic bands associated with the BDNPA at $1464 \mathrm{~cm}^{-1}$ (- $\mathrm{CH}_{3}$ scissoring), 1093 and $1014 \mathrm{~cm}^{-1}$ (-C-O-) and at $910 \mathrm{~cm}^{-1}$ ($\mathrm{CNO})$ decrease. At the same time, the weak band at $1454 \mathrm{~cm}^{-1}$, associated with $\delta(-\mathrm{CH})$, becomes detectable. These spectral changes suggest that the degradation of BDNPA is faster than that of BDNPF. When the sample was exposed to moisture for 112 days, the spectral changes were not as significantly as expected. We suspect that, since the aging experiment was conducted in the confined environment, the initial oxygen present in the sample was consumed as the aging progressed, leading to slowing down of the NP degradation. Nevertheless, from these observations it is clear that when NP is exposed to the humidity condition, it degrades much faster than when it is exposed to either air or water. As the NP molecules degrade into the fragments, as proposed in Schemes A.2-A.6 in Part A of this series and in Scheme B.2 in this study, the reactive fragments will attack nearby polymeric materials. These observations explain why the Estane samples aged 
under $70 \% \mathrm{RH}$ and $70{ }^{\circ} \mathrm{C}$ conditions were severely degraded within a short period of time.[11, 13, 14] Within 4 months, the molecular weight of the polymer samples decreases from 77 to $7 \mathrm{kDalton}$. The Estane polymer was completely degraded through both the hydrolysis and the oxidative reaction pathways.[14]

\section{Summary and Future Work}

As a continuation of our previous work,[1] we investigated the effects of temperature and aging on the NP degradation under water and high humidity conditions at 38, 55 and $70{ }^{\circ} \mathrm{C}$. Similar to the previous studies in Air and under $\mathrm{N}_{2}$ atmosphere, we found that the HONO elimination is the initial step of the NP degradation also in the presence of water. However, the presence of water alters the decomposition pathway for HONO and makes the environment more acidic, which accelerates the structure rearrangement and results in the formation of byproducts with poly-OH functional group. The formation of these polar groups enhances the water solubility in the aged samples, which further accelerates its degradation. On the other hand, the physical state of the water molecules also plays an important role in including or excluding the oxygen in the NP degradation. When the baseline NP is in direct contact with the liquid water, the water layer creates a barrier between the NP and oxygen source, air. On the other hand, when the water molecules are in the vapor phase, water vapor and other gas molecules will attack NP simultaneously even though at moderate temperatures $(<70 \mathrm{C})$. The degradation is particularly rapid when the vapor phase contains oxygen.

In Parts $\mathrm{A}$ and $\mathrm{B}$ of this series of studies, we demonstrated that the environmental conditions play significant role in determining the mechanism of the NP degradation. At $70{ }^{\circ} \mathrm{C}$ or below, the rate of the NP degradation increases in the following order: nitrogen $<$ water $<$ air $<$ water vapor + air.

In real world conditions, NP is typically confined within a solid mixture where the oxygen molecules may be scavenged over time. Therefore, the degradation of NP in the energetic formulas, such as PBX 9501, most likely proceeds through the reaction pathways similar to those we observed under the $\mathrm{N}_{2}$ and humidity atmosphere. Also, the NP degradation in the mixtures may not be as rapid as observed in the water vapor + air atmosphere. Nevertheless, over a long period of time, the isomers, intermediates, and the 
products of degradation will gradually accumulate within the headspace and condensed phases. This study demonstrates that water molecules can be detected in the aged samples regardless of the surrounding environment. Water, together with acidic molecules such as $\mathrm{HNO}_{\mathrm{x}}$ and organic acids, will degrade not only the Estane polymer, but also other adjacent polymeric materials.[17, 18]

With the key insights about the mechanisms of the NP degradation in various environments, found in Parts A and B of these studies, we are now well positioned to quantitatively analyze the kinetics of the degradation processes, which is the goal of our future study. To extract the rates of the individual degradation steps and the overall process, the evolution of the various spectral signatures for all components will be analyzed as a function of time. The results of the analysis will be used to develop a model for predicting the compositions and properties of BDNPA and BDNPF, and the rates of generation of various reactive byproducts under real world environmental conditions. With the better understanding of the NP degradation and potential interactions of degradation byproducts with various components of the energetic mixtures, the theoretical models for predicting the shelf-life of PBX 9501 and nearby polymeric materials can be developed, validated and, eventually optimized.

\section{Acknowledgements}

We thank Darla Thompson and Annie Giambra for sharing their NP samples aged under high humidity at $70{ }^{\circ} \mathrm{C}$ and thank Andrea Labouriau for collecting ${ }^{1} \mathrm{H}$ NMR spectra for the hydrated samples. We also wish to thank Thomas Zocco for his support in executing this work. This work is funded by enhanced surveillance campaign (C8) and the US Department of Energy's National Nuclear Security Administration under the contract DE-AC52-06NA25396.

\section{References:}

[1] Yang D, Pacheco R, Edwards S, Henderson K, Wu R, Labouriau A, et al. Thermal Degradation of a Eutectic Mixture of Bis(2,2-dinitropropyl)acetal and Bis(2,2dinitropropyl)formal: Part A. Degradation Mechanisms in Air and under Nitrogen Atmosphere. Polymer Degradation and Stability. 2016 (submitted). 
[2] Salazar MR, Pack RT. Degradation of a Poly(ester urethane) Elastomer. II. Kinetic Modeling of the Hydrolysis of a Poly(butylene adipate). J of Polymer Science: Part B: Polymer Physics. 2002;40:8.

[3] Salazar MR, Lightfoot JM, Russell BG, Rodin WA, McCarty M, Wrobleski DA, et al. Degradation of a poly(ester urethane) elastomer. III. Estane 5703 hydrolysis:

Experiments and modeling. Journal of Polymer Science, Part A: Polymer Chemistry. 2003;41:1136-51.

[4] Salazar MR, Kress JD, Lightfoot JM, Russell BG, Rodin WA, Woods L.

Experimental Study of the Oxidative Degradation of PBX 9501 and its Components. Propellants, Explosives, Pyrotechnics. 2008;33:20.

[5] Salazar M, R., Kress JD, Lightfoot JM, Russell BG, Rodin WA, Woods L. Lowtemperatuer oxidative degradation of PBX 9501 and its components determind via molecular weight analysis of the Poly[ester urethane] binder. Polymer Degrdation and Stability. 2009;94:9.

[6] Wrobleski DA, Langlois DA, Orler EB, Labouriau A, Uribe M, Houlton R, et al. Accelerated Aging and Characterization of a Plasticized Poly(ester urethane) Binder. In: Celina MC, Wiggins JS, Billingham NC, editors. Polymer Degrdation and Performance. American Chemical Society; Chicago, IL, 2008. Chapter 16, p181.

[7] Wrobleski D, Langlois D, Orler E, Dattelbaum D, Small J. Application of 15N labeling for oxidative degradation study of a plasticized poly(ester urethane). Polymer Preprints. 2004;45:2.

[8] Finger M. Properties of Bis(2,2-Dinitropropyl)Acetal and Bis(2,2-

Dintropropyl)Formal, Eutectic mixture. Internal Report: UCID-16088, Lawrence Livermore Laboratory; Livermore, California, 1972. p. 16.

[9] Salazar MR, Thompson SL, Laintz KE, Meyer TO, Pack RT. Degradation of a poly(ester urethane) elastomer. IV. Sorption and diffusion of water in PBX 9501 and its components. Journal of Applied Polymer Science. 2007;105:14.

[10] Rauch RB, Behrens R. Vapor Pressures, Mass Spectra and Thermal Decomposition Processes of Bis(2,2-Dintropropyl)acetal (BDNPA) and Bis(2,2-Dinitropropyl)formal (BDNPF). Propellants, Explosives, Pyrotechnics 2007;32:20.

[11] Thompson DG, Deluca R. Accelerated Aging of PBX 9501 from Universal Hemispheres. Internal Reprot: LA-CP-14-00015, Los Alamos National Laboraotry; - Los Alamos, New Mexico, 2014. p. 20.

[12] Greenspan L. Humidity Fixed Points of Bindary Saturated Aqueous Solutions. J of Reserach of the National Bureau of Standards - A Physics and Chemistry. 1977;81A:8.

[13] Giambra AM. Summary of Aging Stuidy for PBX 9501 Project. Final Analytical Report for Lab. 51578, WX-7, Los Alamos National Laboratory; December 2012. p. 29. [14] Yang D. Comparison between Natural and Accelerated Aging of Poly(ester urethane). Internal report: LA-UR-14-20362, Los Alamos National Laboratory; Los Alamos, New Mexico, 2014. p. 22.

[15] Water vapor IR spectrum: NIST Chemistry WebBook, http://webbook.nist.gov/cgi/cbook.cgi?ID=C7732185\&Units=SI\&Type=IRSPEC\&Index=0\#IR-SPEC. 2016.

[16] Venyaminov SY, Prendergast FG. Water (H2O and D2O) Molar Absorptivity in the 1000-4000 cm-1 Range and Quantitative Infrared Spectroscopy

of Aqueous Solutions. Analytical Biochemistry. 1997;248:12. 
[17] Yang D, Hubbard KM, Henderson KC, Labouriau A. Thermal and Chemical Stabilization of Ethylene/Vinyl Acetate/Vinyl Alcohol (EVA-OH) Terpolymers Under Nitroplasticizer Environments. J of Applied polymer Science. 2014;132:17. [18] Patterson BM, Havrilla GJ, Schoonover JR. Elemental and Molecular Characterization of Aged Polydimethylsiloxane Foams. Applied Spectroscopy. 2006; 60(10):1103 


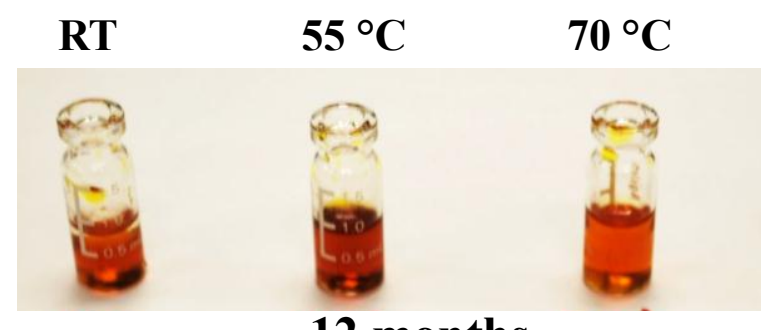

\section{2 months}
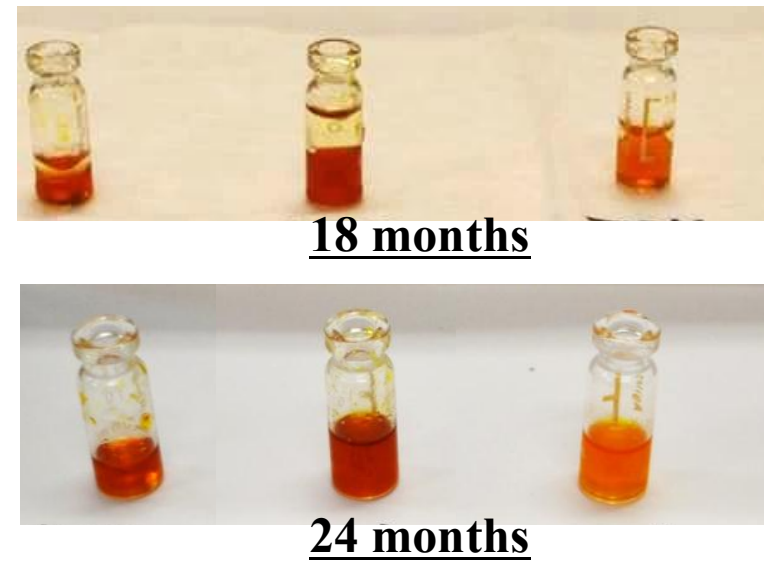

Figure 1. COLOR CHANGES IN THE HYDRATED NPS AGED AT DIFFERENT TIME AND TEMPERATURES.

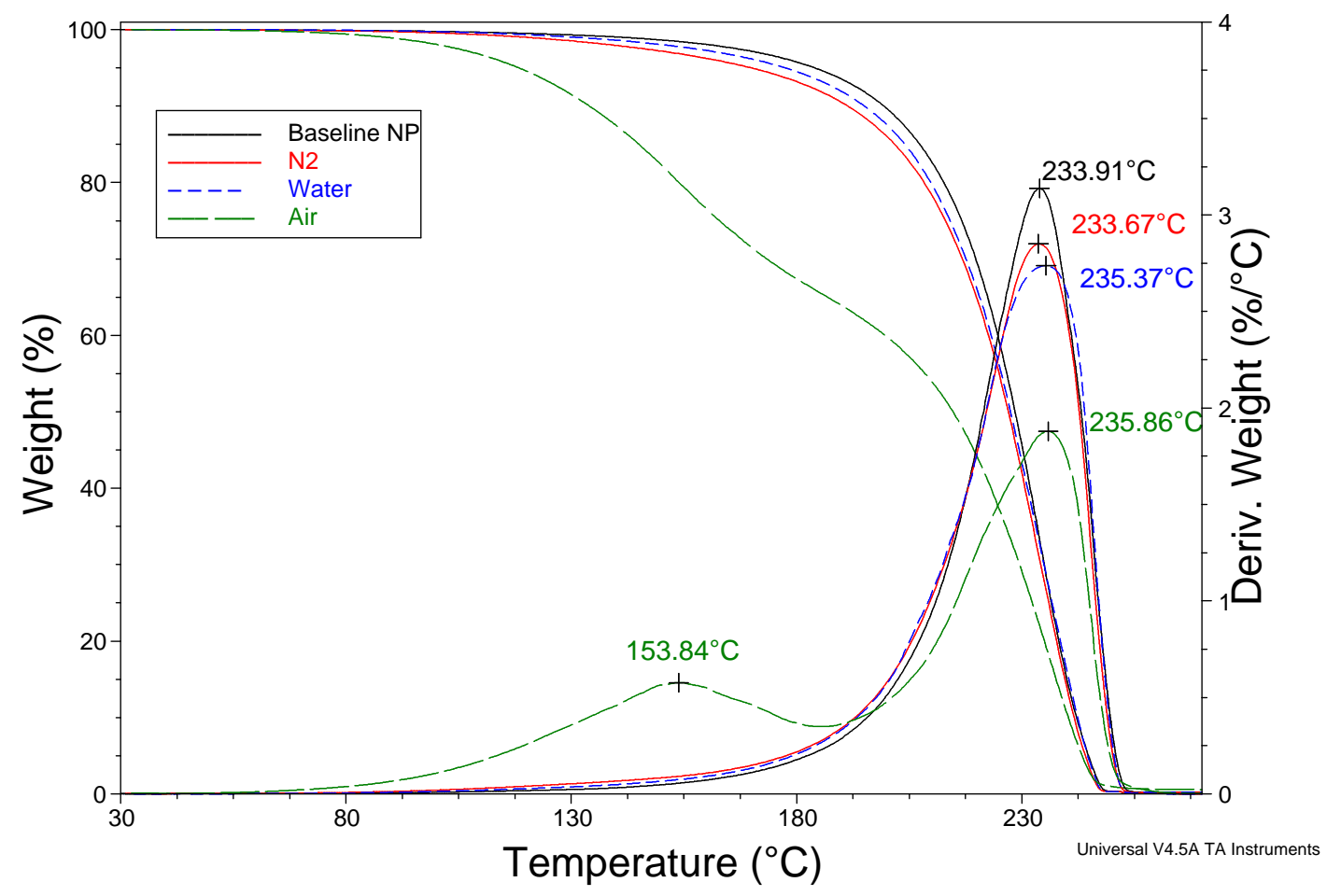

Figure 2. TGA results of baseline NP, and three samples aged at $70{ }^{\circ} \mathrm{C}$ for 24 months under different environments. 

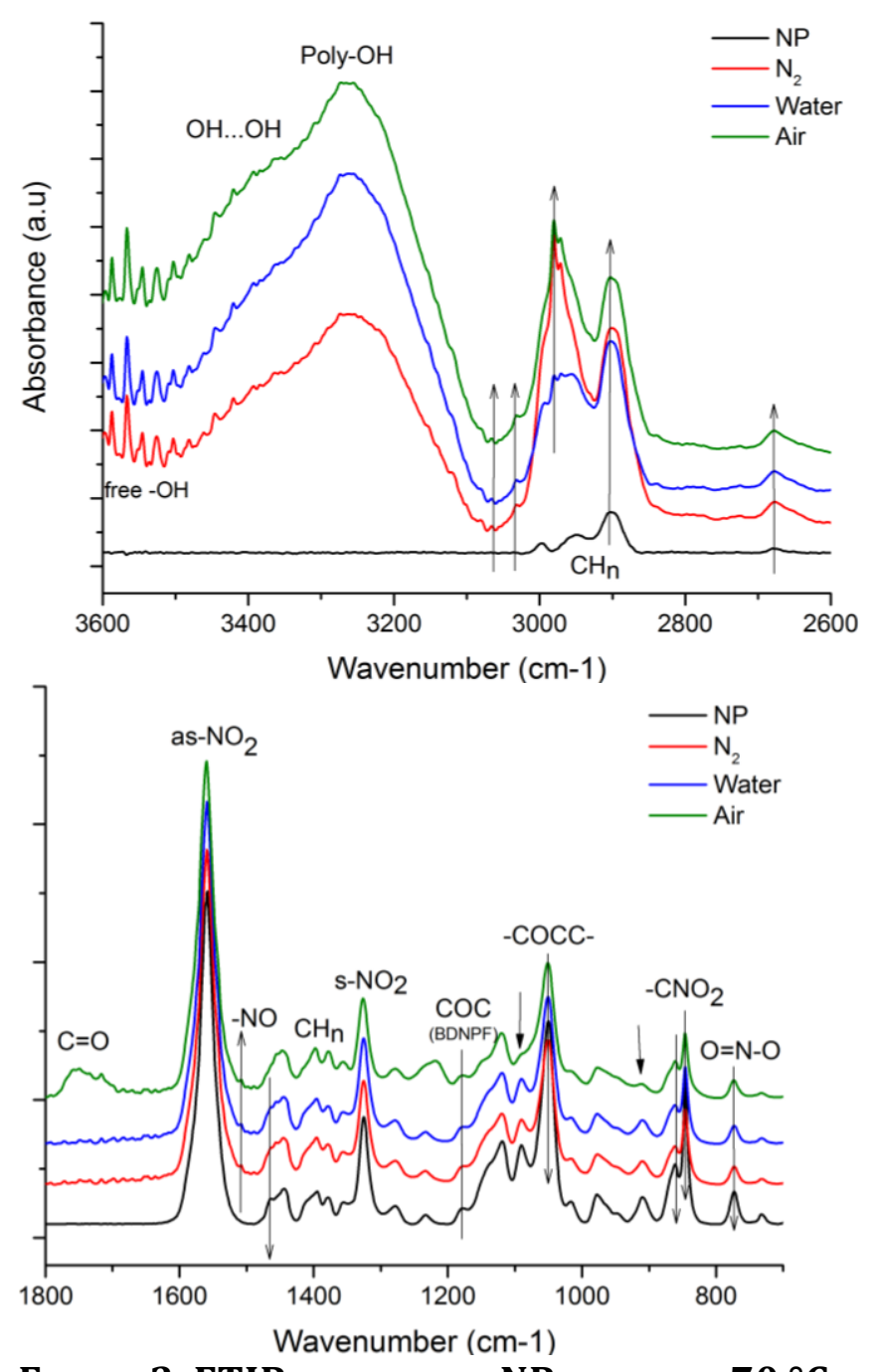

FIGURE 3. FTIR SPECTRA OF NPS AGED AT $70^{\circ} \mathrm{C}$ UNDER DIFFERENT ENVIRONMENTS FOR 24 MONThS. All SPECTRA ARE NORMAlized to AS-NO 2 PEAK AT $\sim 1560 \mathrm{CM}^{-1}$. In the Hregion, the spectra were multiplied 10 times to better illustrate the spectral changes. The same methodology is applied to the rest FTIR spectra in this document. 

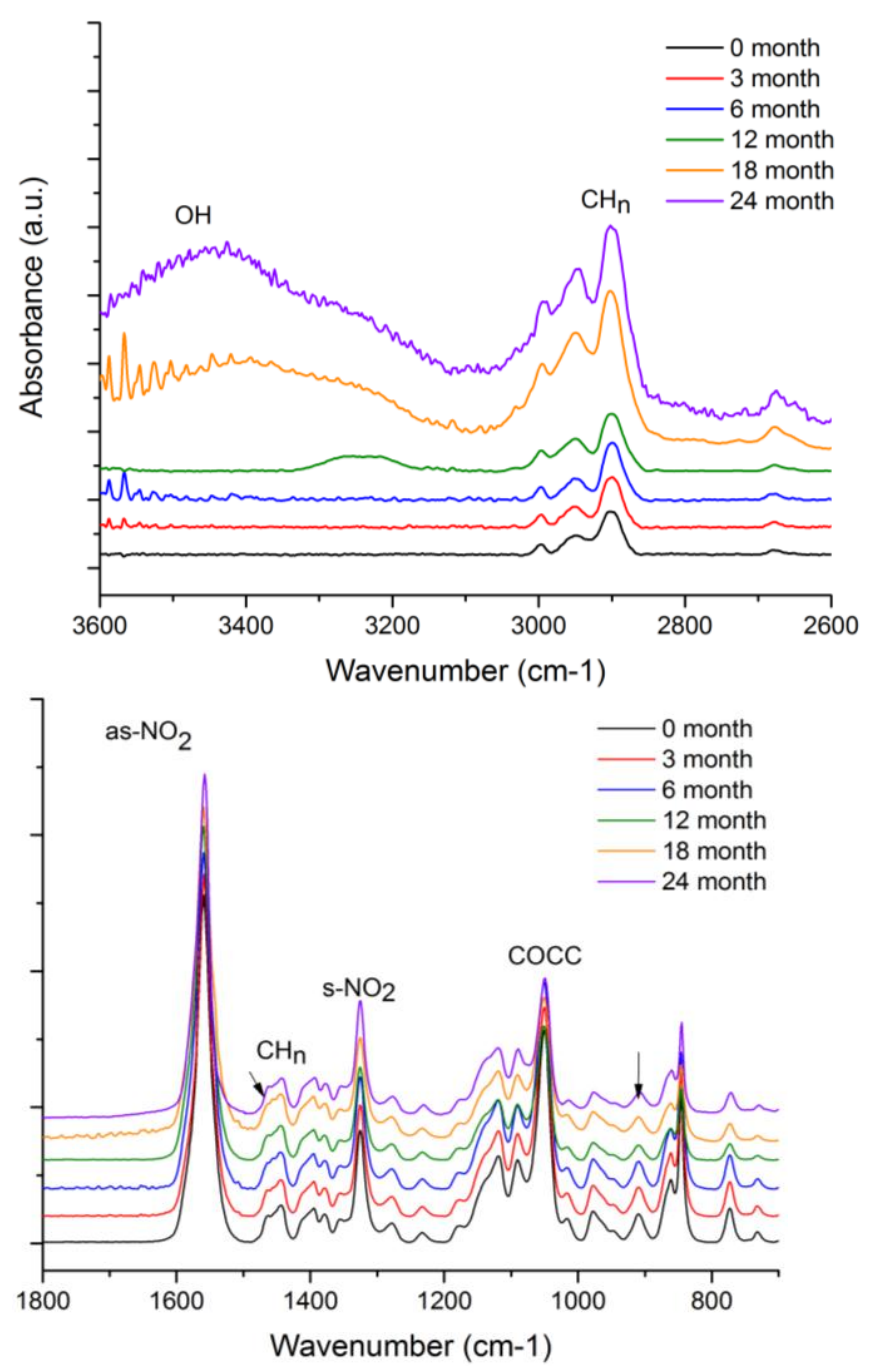

(A) $\mathrm{RT}$ 

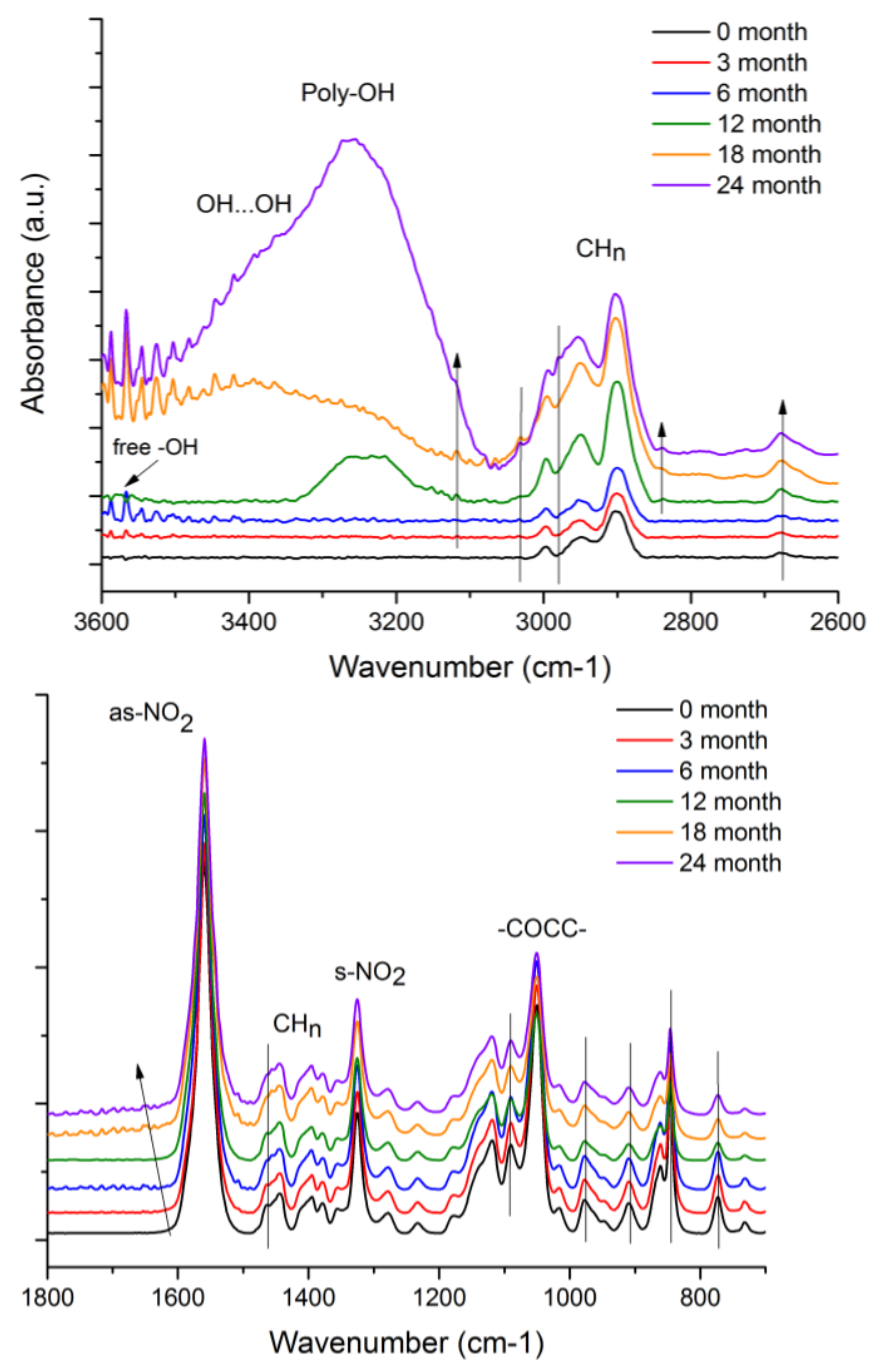

(b) $55^{\circ} \mathrm{C}$ 

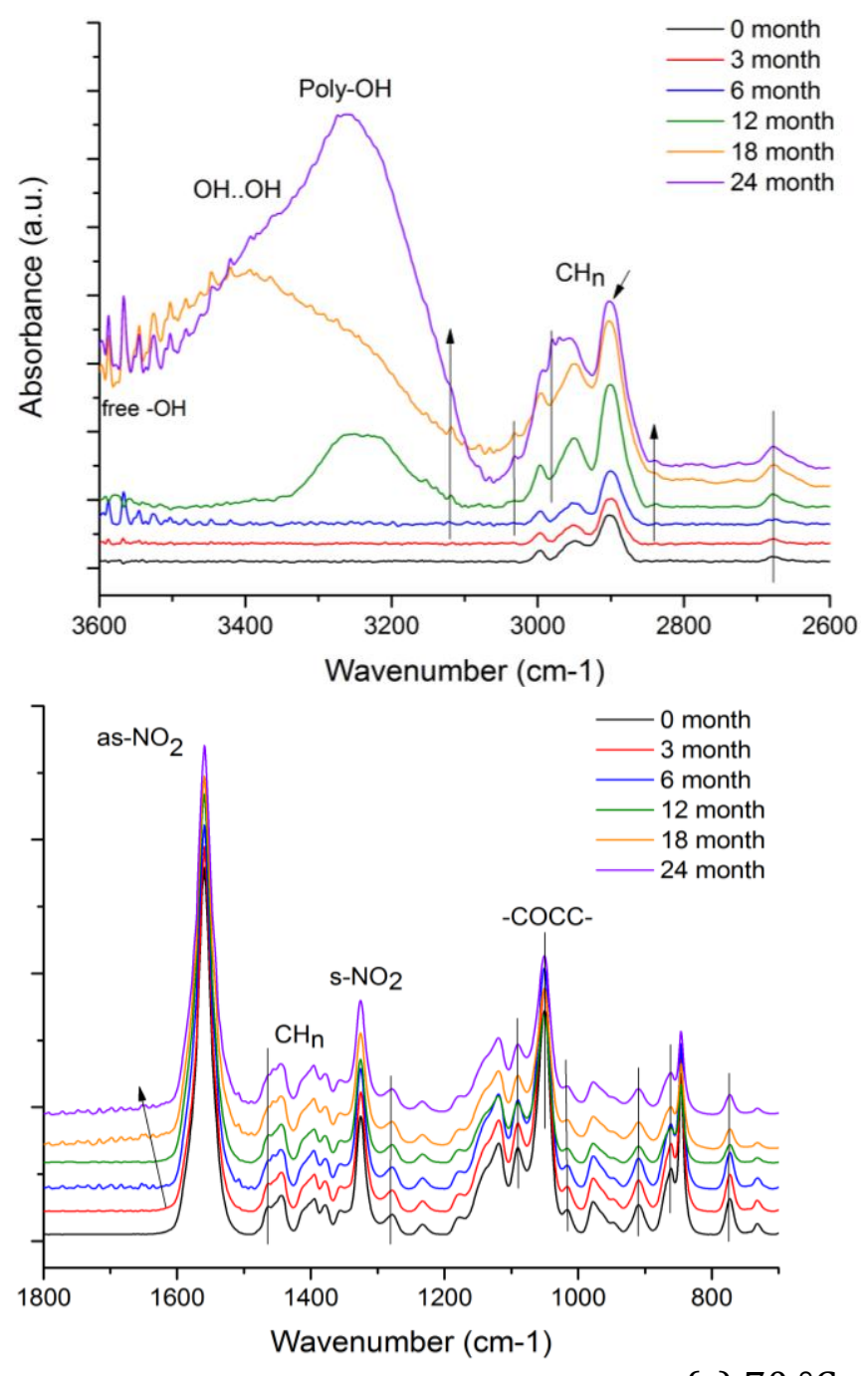

(c) $70{ }^{\circ} \mathrm{C}$

FIGURE 4. EFFECTS OF AGE AND TEMPERATURE ON THE FTIR SPECTRA OF NP SAMPLES EXPOSED TO WATER. 


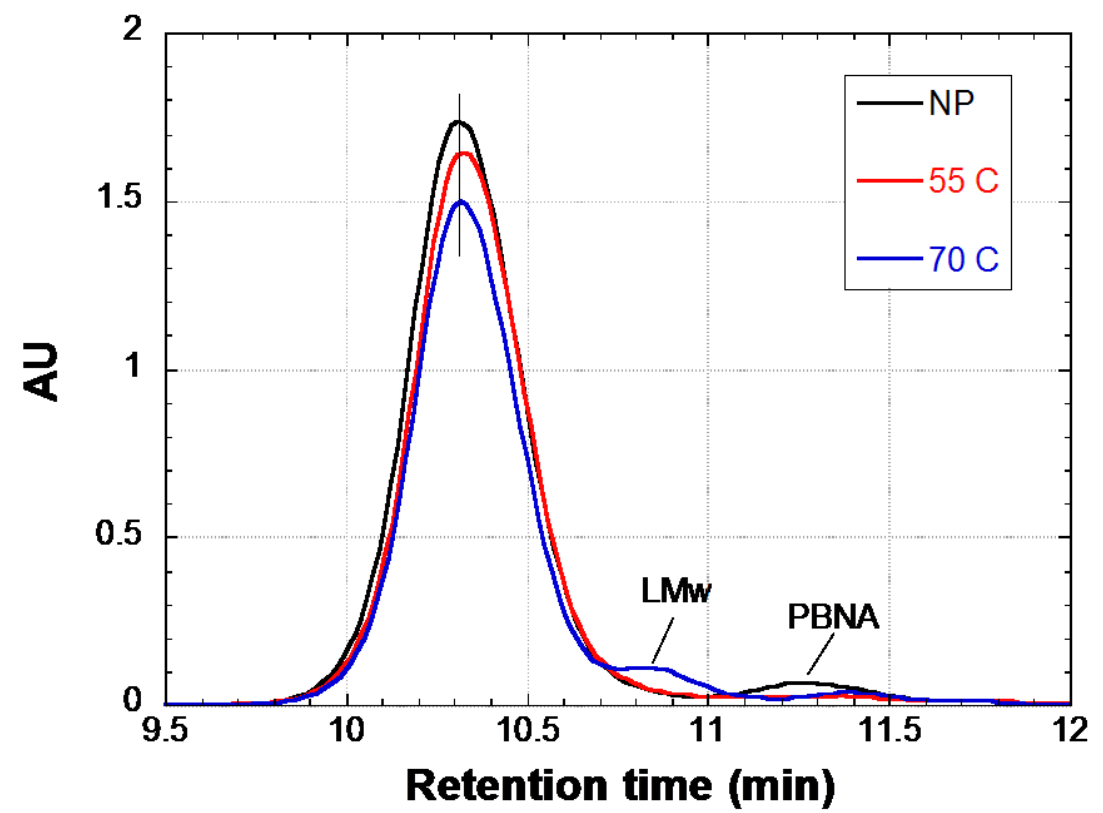

FiguRE 5. GPC RESULTS OF HYDRATED NPS AGED AT 55 AND $70{ }^{\circ} \mathrm{C}$ FOR 24 MONTHS.

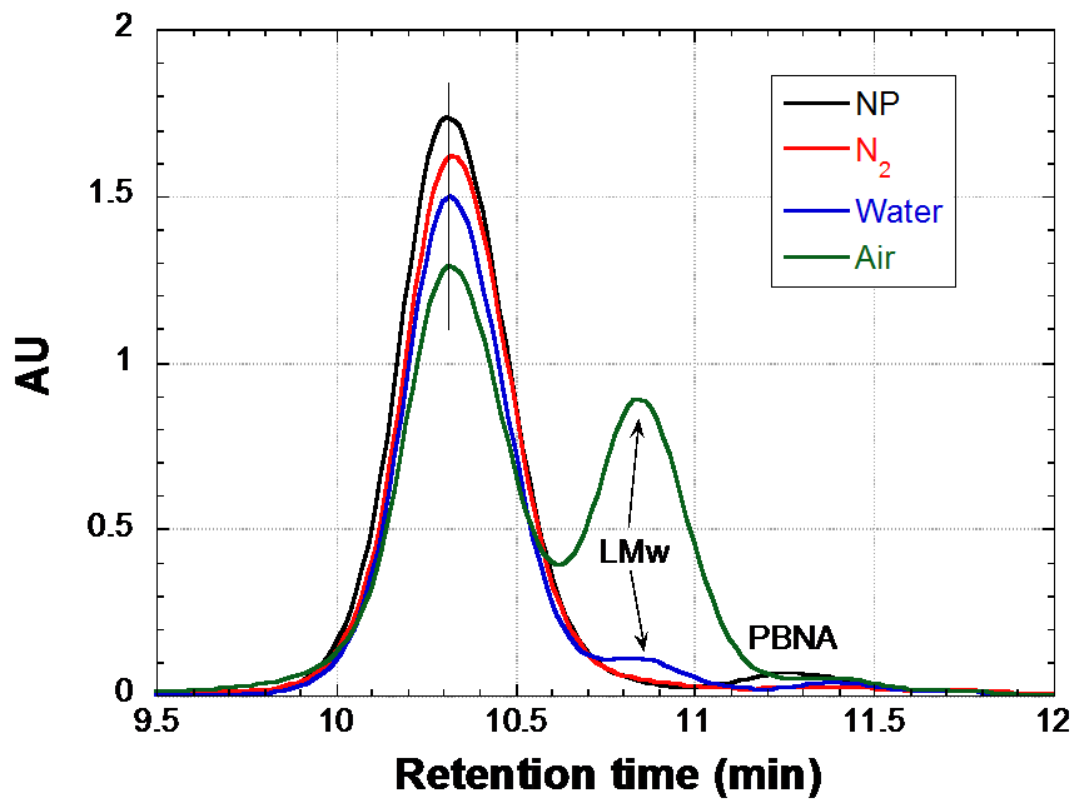

FIGURE 6. GPC RESULTS OF THE SAMPLES AGED UNDER DIFFERENT ENVIRONMENTS AT $70{ }^{\circ}$ C FOR 24 MONTHS. 


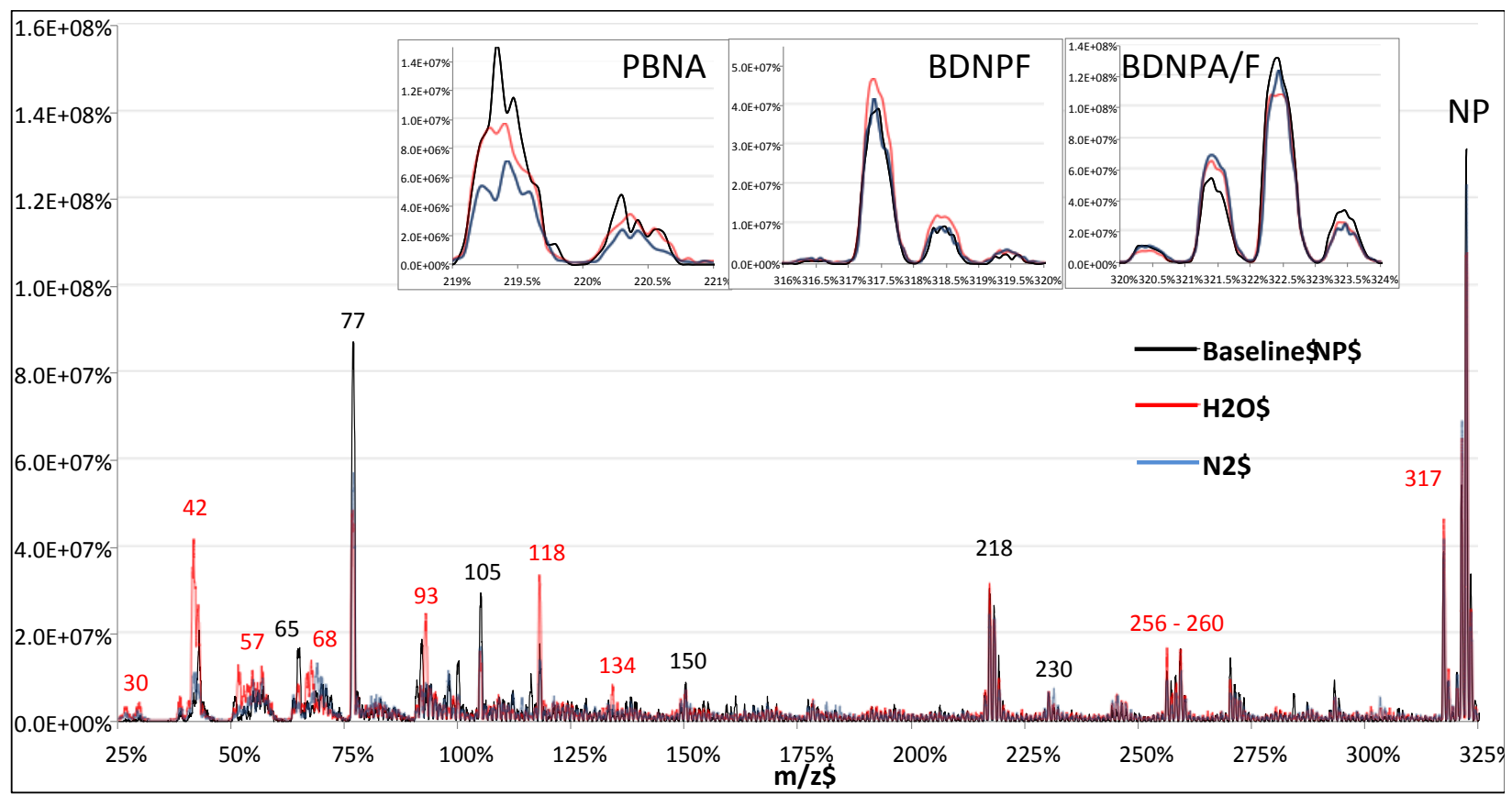

(a) Hydrate vs. $\mathrm{N}_{2}$ samples

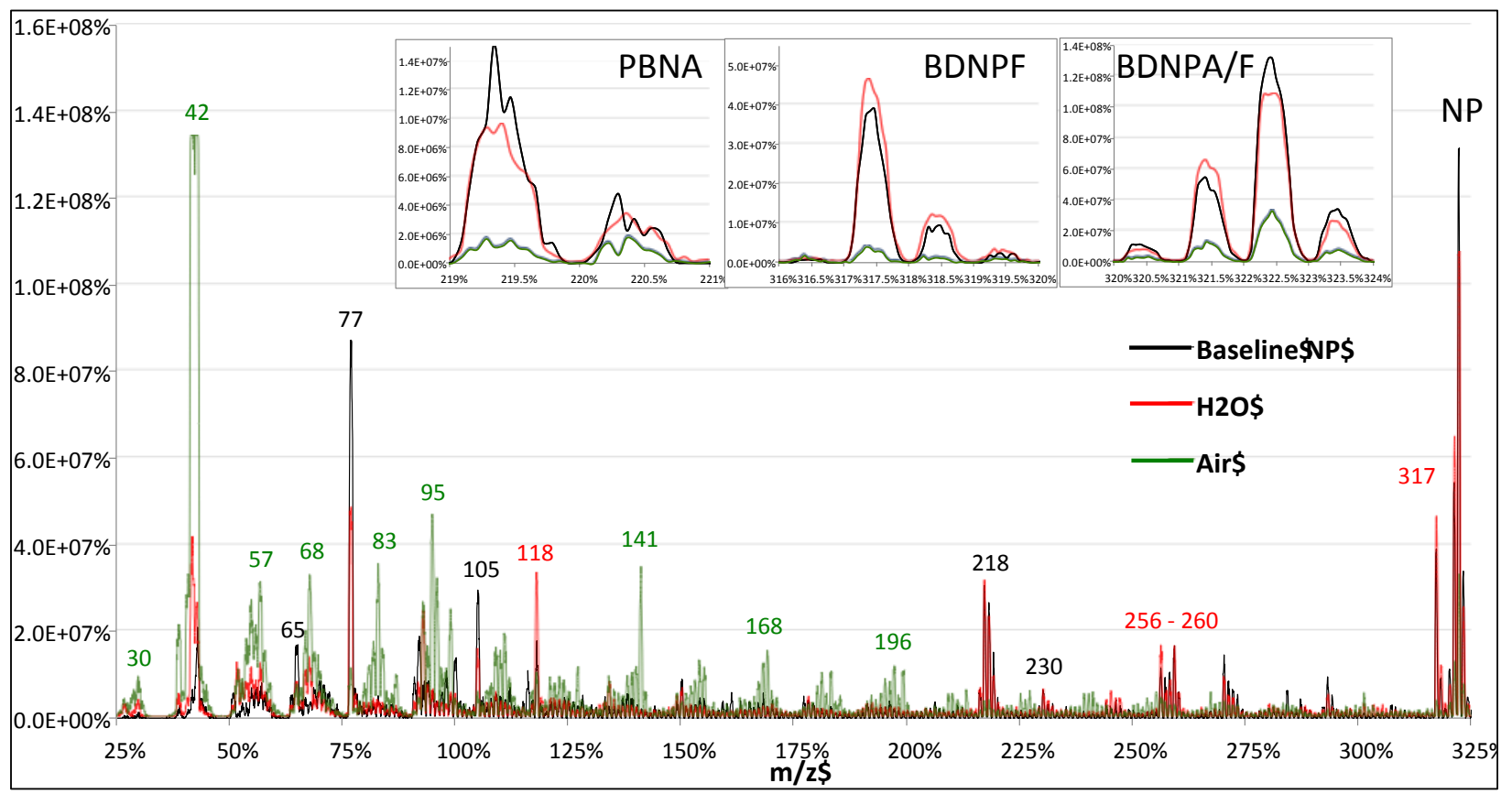

(b) Hydrated vs. Air samples

FIGURE 7. ESI-MASS SPECTRA OF NP AGED UNDER DIFFERENT ENVIRONMENTS AT $70{ }^{\circ}$ C FOR 24 MONTHS. 


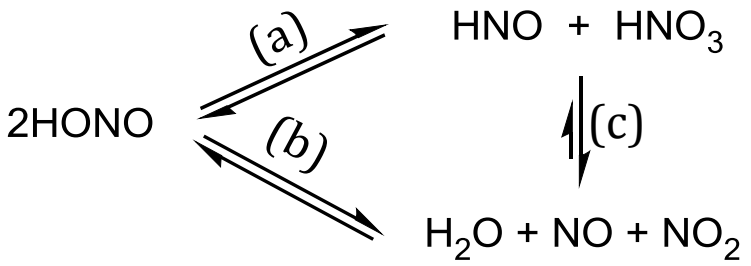

Scheme B.1. The decomposition pathways of HONO molecules.

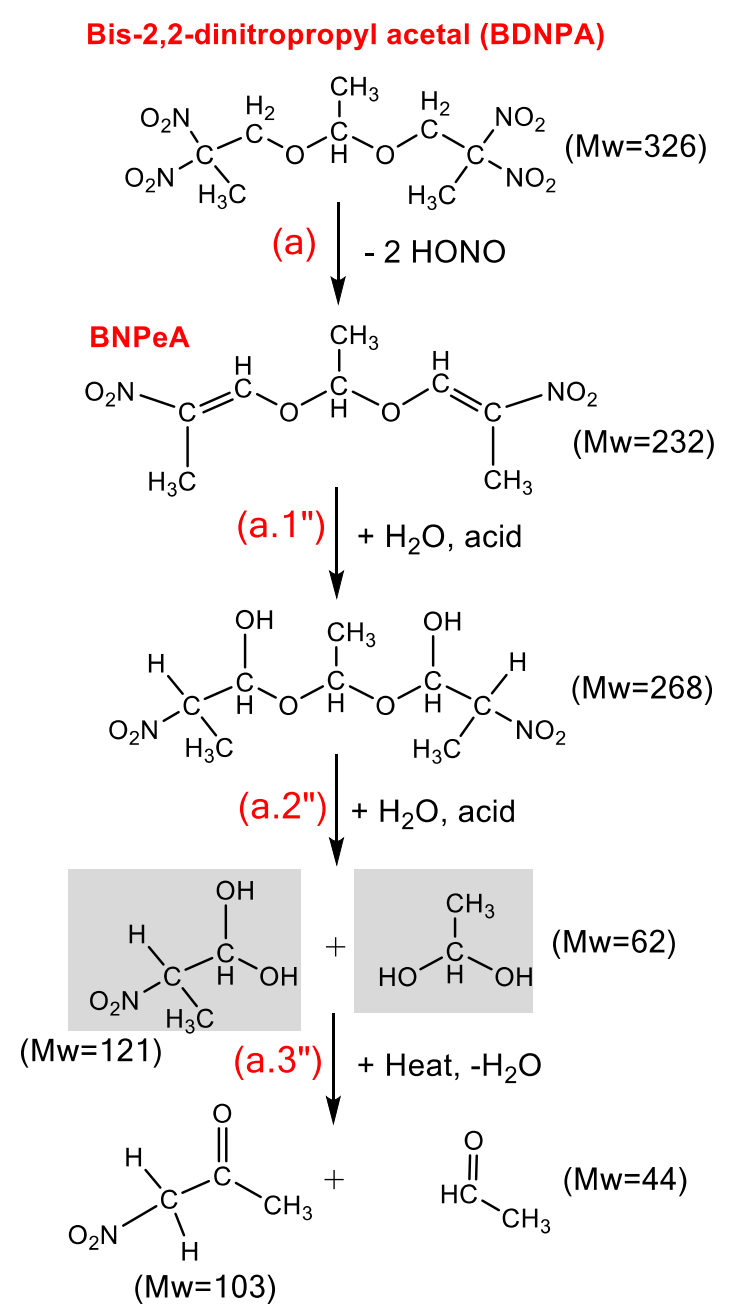

Bis-2,2-dinitropropyl formal (BDNPF)

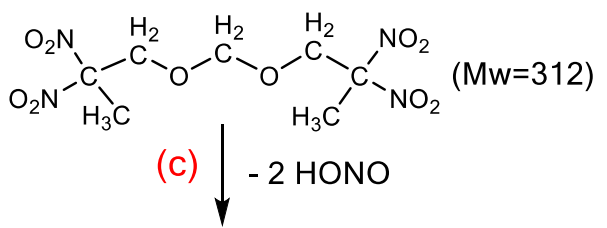<smiles>C/C(=C\OCO/C=C(\C)[N+](=O)[O-])[N+](=O)[O-]</smiles>

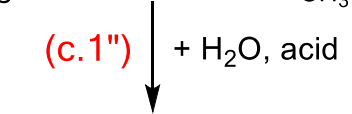<smiles>CC(OCOC(O)C(C)[N+](=O)[O-])C(O)[N+](=O)[O-]</smiles>

$$
\text { (c.2") } \downarrow+\mathrm{H}_{2} \mathrm{O} \text {, acid }
$$

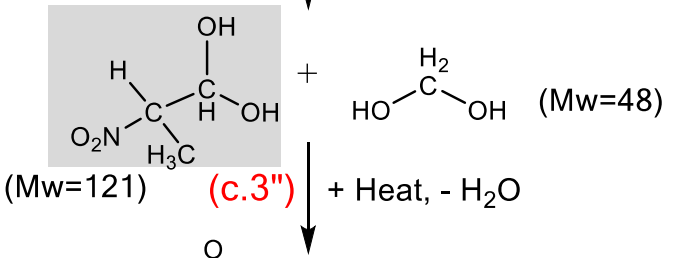<smiles>C[14CH2]CC=O</smiles>

Scheme B.2. The water addition reaction to BNPeA and BNPeF under an acidic condition. 


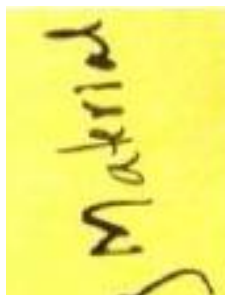

Baseline 18 day $\quad 32$ day 52 day $\quad 86$ day 112 day

Figure 8. COLOR CHANGES IN THE AGED SAMPLES UNDER 74\% RH AT $70{ }^{\circ} \mathrm{C}$ FOR DIFFERENT TIMES. THE PHOTO WAS CITED FROM REFERENCE[13].

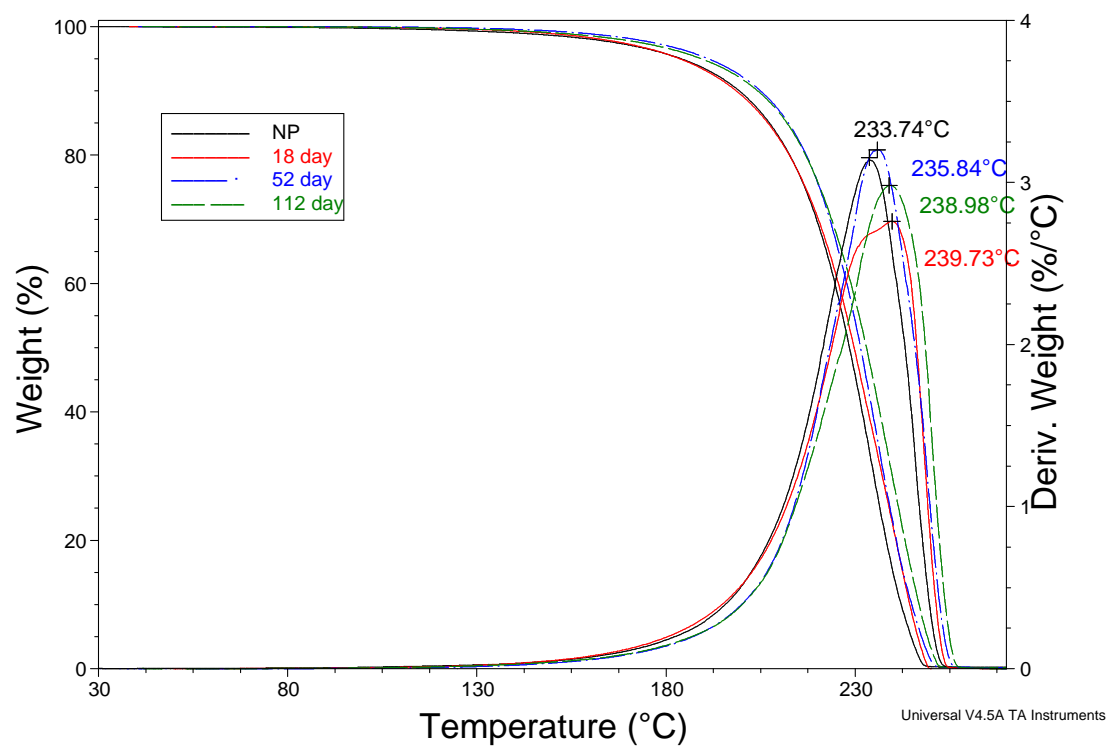

FIgURE 9. TGA RESULTS OF NPS AGED UNDER $74 \%$ RH AT $70{ }^{\circ} \mathrm{C}$ FOR DIFFERENT TIMES 

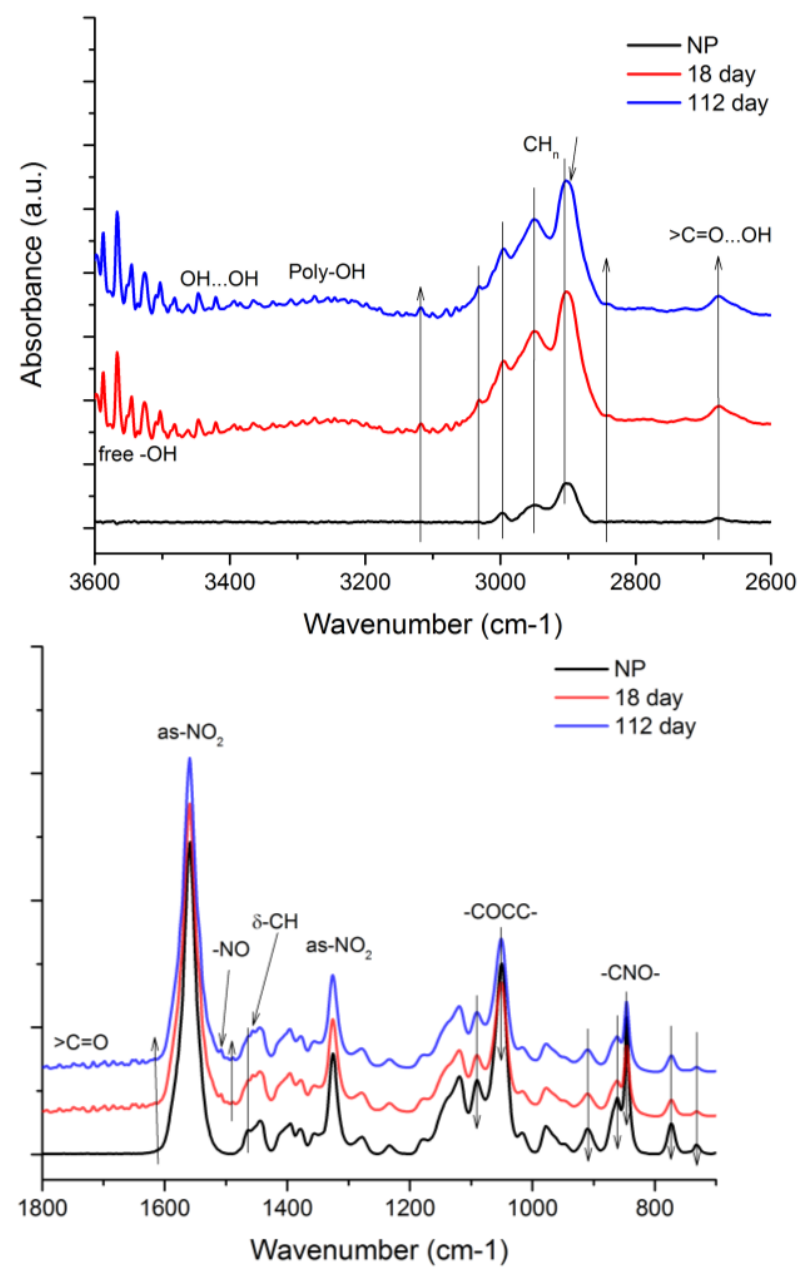

FIGURE 10. FTIR SPECTRA OF NPS AGED UNDER $74 \%$ RH AT $70{ }^{\circ} \mathrm{C}$ FOR DIFFERENT TIMES. 